\title{
Сравнительная эффективность применения в птицеводстве зарубежных и отечественных кокцидиостатиков с идентичными действующими веществами
}

Бирюков И.М., научный сотрудник отдела паразитологии

Всероссийский научно-исследовательский ветеринарный институт птицеводства (ВНИВИП) - филиал ФНЦ «ВНИТИП» РАН

Аннотация: Проведено исследование противокоцидийной эрфективности зарубежных и отечественных кокиидиостатиков с идентичными действующими веществами (салиномицин, диклазурил, монензин, мадурамицин). Материалом для исследования служила полевая культура кокцидий, содержащая видь Eimeria acervulina и E. tenella. Эта смесь была быделена из проб помета с подстилочным слоем от разновозрастной птицы, доставленных из одного из российских птицехозяйств. Культура была оттитрована на LD50 на иьллятах-бройлерах 6 возрасте 10 дней. Антикокцидийную активность препаратов изучали на 10 группах цыплят-бройлеров 12-дневного возраста по 6 голов в каждой. Проводили взвешивание цьплят, начинали давать препараты за сутки до заражения полевым изолятом 6 дозе $L D_{50}$ и 6 течение последующих 10 дней. Учитывали летальность и прирост живой массы 6 опытных группах за этот период, проводили патологоанатомическое бскрытие павщей птицы. Уровень антикокцидийной эфрективности препаратов рассчитывали б баллах противокоцидийного индекса по Крылову. Было установлено, что препараты отечественного производства по противококцидийной активности не уступают сбоим зарубежным аналогам, наиболее эфрективными оказались препараты на основе салиномицина.

Ключевые слова: кокцидиоз, эймерии, антикокцидийные препараты, салиномицин, диклазурил, монензин, мадурамицин.

Введение. Среди паразитарных заболеваний, распространенных в птицеводстве, кокцидиоз занимает одно из главенствующих мест. Кокцидиоз приобрел такое большое значение в птицеводстве только в результате перехода этой отрасли на промышленную основу, при которой концентрация птицы на небольшой площади приводит к сильнейшему воздействию паразитов на птицепоголовье, в результате чего возникают эпизоотии различных этиологий, что приводит к широкомасштабным экономическим потерям.

В мировом масштабе отрасль птицеводства от кокцидиоза и борьбы с ним ежегодно теряет от 1,5 до 3,0 млрд. долларов США, что указывает на острую необхо- димость разработки более эффективных стратегий борьбы с этими паразитами [1].

Начиная с конца 40-х годов прошлого века и до сегодняшнего времени первое место в профилактике кокцидиоза отдают антикокцидийным препаратам. Несмотря на немалый ассортимент средств по профилактике кокцидиоза, вопрос об устойчивости паразитов к противококцидийным препаратам и ее передаче следующим поколениям становится все более острым [2].

$\mathrm{K}$ настоящему времени не существует способов предупреждения возникновения устойчивости к кокцидиостатикам. Только поиск новых и усовершенствование имеющихся препаратов позволит отсрочить сроки развития устойчивости паразита к препаратам.

Цель исследования: определить противокоцидийную эффективность зарубежных и отечественных кокцидиостатиков с идентичными действующими веществами (салиномицин, диклазурил, монензин, мадурамицин).

материал и методика исследований. Материалом для исследования служили пробы помета с подстилочным слоем от птицы из разных возрастных групп, полученные из одного из птицехозяйств на территории Российской Федерации. Используя общепринятые методики, из материала выделяли, изолировали и 
размножали культуру кокцидий.

Видовое типирование культуры кокцидий проводили по морфологическим свойствам ооцист, по длительности препатентого периода, а также учитывали локализацию кокцидий в различных отделах кишечника птицы. Была выделена смесь полевых культур кокцидий Eimeria acervulina и $E$. tenella. Выделенная смесь полевых культур была оттитрована на $\mathrm{LD}_{50}$ путем дробного заражения интактных в отношении кокцидий 10-дневных цыплят-бройлеров.

Тестирование антикокцидийной активности изучаемых препаратов проводили на бройлерах 12-дневного возраста, полученных из хозяйства, благополучного по заболеваниям инвазионной и инфекционной этиологии.

В 12-дневном возрасте цыплят взвешивали, делили на контрольную незараженную, контрольную зараженную и опытные группы зараженные, которым давали препараты за сутки до заражения, и затем заражали полевым изолятом эймерий в дозе $\mathrm{LD}_{50}$.

После 10 дней применения кокцидиостатиков и наблюдений за птицей проводили ее взвешивание, учитывали летальность, проводили патологоанатомическое вскрытие павшей птицы.

Эффективность антикокцидийной активности препаратов рассчитывали в баллах противокоцидийного индекса (ПКИ) по методу, предложенному М.В. Крыловым (1969), который учитывает выживаемость цыплят и изменение их живой массы [3]:

ПКИ (баллы $)=A+\left(M / M_{1}\right) \times 100$;

где: А - выживаемость цыплят в опытной группе, \%; М - относительный прирост живой массы цыплят в опытной группе, \%; $\mathrm{M}_{1}$ - относительный прирост живой массы цыплят в незараженной контрольной группе, \%.

Исследовали следующие пре-

\begin{tabular}{|c|c|c|c|c|c|}
\hline \multirow[t]{2}{*}{ Группа } & \multirow{2}{*}{$\begin{array}{c}\text { Препарат } \\
\text { (действующее вещество) }\end{array}$} & \multicolumn{2}{|c|}{$\begin{array}{l}\text { Количество } \\
\text { особей, гол. }\end{array}$} & \multicolumn{2}{|c|}{$\begin{array}{c}\text { Средняя живая } \\
\text { масса, r }\end{array}$} \\
\hline & & $\begin{array}{l}\text { в начале } \\
\text { опыта }\end{array}$ & $\begin{array}{l}\text { в конце } \\
\text { опыта }\end{array}$ & $\begin{array}{l}\text { в начале } \\
\text { опыта }\end{array}$ & $\begin{array}{l}\text { в конце } \\
\text { опыта }\end{array}$ \\
\hline 1 & Контроль чистый & 6 & 6 & 466 & 852 \\
\hline 2 & Контроль зараженный & 6 & 4 & 478 & 781 \\
\hline 3 & Пулкокс 40\% (монензин) & 6 & 5 & 491 & 793 \\
\hline 4 & Сакокс 120 (салиномицин) & 6 & 6 & 491 & 789 \\
\hline 5 & Кокцирил 0,5\% (диклазурил) & 6 & 5 & 490 & 793 \\
\hline 6 & Юмамицин (мадурамицин) & 6 & 6 & 490 & 740 \\
\hline 7 & Эймицид (салиномицин) & 6 & 6 & 490 & 780 \\
\hline 8 & Мадефорд (мадурамицин) & 6 & 6 & 491 & 708 \\
\hline 9 & Мелазит 40\% (монензин) & 6 & 6 & 458 & 689 \\
\hline 10 & Кокцимакс (диклазурил) & 6 & 5 & 456 & 726 \\
\hline
\end{tabular}

параты (в скобках приводятся их действующие вещества):

- зарубежного производства: Пулкокс 40\% (монензин), Сакокс 120 (салиномицин), Кокцирил 0,5\% (диклазурил), Юмамицин (мадурамицин);

- отечественного производства - Эймицид (салиномицин), Мадефорд (мадурамицин), Мелазит 40\% (монензин), Кокцимакс (диклазурил).

Исследуемые кокцидиостатики относят к ионофорным антибиотикам и препаратам, полученным химическим синтезом. Диклазурил - синтетическое соединение группы триазинов, действующее на бесполые или половые стадии кокцидий, блокируя выделение ооцист [4]. Салиномицин и монензин - моновалентные ионофоры, направленные на нарушение проницаемости биологической мембраны паразита для катионов $\mathrm{Na}^{+}$ и $\mathrm{K}^{+}$, что вызывает осмотические поражения, приводящие к гибели паразита [5]. Полиэфирный антибиотик мадурамицин является моновалентным ионофоргликозидом, имеющим механизм действия, сходный с салиномицином и монензином [6].

Результаты исследований и их обсуждение. Падеж и данные по живой массе цыплят представлены в табл. 1. В группе зараженного контроля пало больше всего цыплят (2 гол. из 6), что свидетельствует о сохранности вирулентных свойств выделенной смеси полевых культур кокцидий $E$. acervulina и $E$. tenella. Также гибель птицы (по 1 гол.) отмечалась в группах с монензином и диклазурилом, что говорит о лишь частичном действии данных антикокцидийных препаратов при заражении цыплят кокцидиями.

Данные по расчету чувствительности изучаемых видов кокцидий к кокцидиостатикам пред-

\begin{tabular}{|c|c|c|c|c|c|}
\hline № гр. Препарат & $\begin{array}{c}\text { Пало, } \\
\text { гол. }\end{array}$ & $\begin{array}{c}\text { Выжило, } \\
\%\end{array}$ & $\begin{array}{c}\text { Отн. } \\
\text { прирост } \\
\text { живой } \\
\text { массы, \% }\end{array}$ & $\begin{array}{c}\text { Среднесут. } \\
\text { прирост } \\
\text { живой массы, } \\
\text { г/гол./сут. }\end{array}$ & $\begin{array}{c}\text { ПКИ, } \\
\text { баллы }\end{array}$ \\
\hline Контроль чистый & 0 & 100 & 82,83 & 38,6 & 200,0 \\
\hline Контроль зараженный & 2 & 66 & 63,39 & 30,3 & 142,5 \\
\hline Пулкокс 40\% (монензин) & 1 & 83 & 61,30 & 30,2 & 157,0 \\
\hline Сакокс 120 (салиномицин) & 0 & 100 & 60,69 & 28,9 & 173,3 \\
\hline Кокцирил 0,5\% (диклазурил) & 1 & 83 & 61,84 & 30,3 & 157,7 \\
\hline Юмамицин (мадурамицин) & 0 & 100 & 51,02 & 25,0 & 161,6 \\
\hline Эймицид (салиномицин) & 0 & 100 & 59,18 & 29,0 & 171,4 \\
\hline Мадефорд (мадурамицин) & 0 & 100 & 44,20 & 21,7 & 153,4 \\
\hline 9 Мелазит 40\% (монензин) & 0 & 100 & 50,44 & 23,1 & 160,9 \\
\hline 10 Кокцимакс (диклазурил) & 1 & 83 & 59,21 & 27,0 & 154,5 \\
\hline
\end{tabular}


ставлены в табл. 2. Кокцидиостатик считается высокоактивным против выделенного паразита, если его ПКИ будет более 180 баллов при уровне заражения в пределах $\mathrm{LD}_{30-50}$ [3].

Наибольшую активность против выделенной смеси кокцидий проявили препараты Сакокс 120 (зарубежный) и Эймицид (отечественный), действующим веществом которых является салиномицин; ПКИ этих препаратов составил 1 73,3 и 171,4 балла соответственно.

Следующими по активности были препараты Юмамицин (мадурамицин, зарубежный) и Мелазит 40\% (монензин, отечественный); ПКИ этих препаратов составил 161,6 и 160,9 балла соответственно. Можно предположить, что процесс формирования приобретенной резистентности к этим препаратам в настоящее время входит в активную фазу.

К импортным кокцидиостатикам Пулкокс 40\% (монензин) и Кокцирил 0,5\% (диклазурил) и отечественным кокцидиостатикам Мадефорд (мадурамицин) и Кокцимакс (диклазурил) у изучаемых кокцидий имелись явные признаки резистентности, поскольку ПКИ для этих препаратов находился в пределах 153,4-1 57,7 балла.

Учитывая то, что Юмамицин и Мелазит 40\% по значению ПКИ находились на границе чувствительности и частичной резистентности к противококцидийным препаратам, их, скорее, можно отнести к группе препаратов, к которым проявляется частичная адаптация паразитов.

Как видно из данных по ПКИ зарубежных и отечественных препаратов кокцидиостатиков, существенной разницы по активности против изучаемой смеси кокцидий между ними не наблюдалось.

Заключение. На основании результатов проведенного исследования можно сделать вывод, что антикокцидийная активность препаратов отечественного производства не имеет существенных отличий от активности их зарубежных аналогов. Можно констатировать, что отечественные кокцидиостатики могут успешно при- меняться в птицехозяйствах для борьбы с кокцидиозом и для его профилактики.

\section{Литература}

1. Shirley M.W., Smith A.L., Blake D.P. Challenges in the successful control of the avian coccidia // Vaccine. - 2007. - V. 25, No 30. - P. 5540-5547.

2. Yadav A., Gupta S.K. Study of resistance against some ionophores in Eimeria tenella field isolates // Vet. Parasitol. - 2001. - V. 102. - P. 69-75.

3. Крылов М.В. Оценка кокцидиостатических свойств препаратов // Ветеринария. - 1969. - №1 0. - С. 48-51.

4. Noack S., Chapman H.D., Selzer P.M. Anticoccidial drugs of the livestock industry // Parasitol. Res. - 2019. - V. 118, No 7. - P. 2009-2026.

5. Kant V., Singh P., Verma P.K., Bais I., Parmar M.S., Gopal A., Gupta V. Anticoccidial drugs used in the poultry: An overview // Sci. Intl. - 2013. - V. 1, No 7. - P. 261-265.

6. Кириллов А.И. Кокцидиозы птиц. М.: Россельхозакадемия, 2008. - С. 104-111.

\section{Для контакта с автором:}

Бирюков Илья Михайлович

E-mail: i_biryukov88@mail.ru

The Comparative Efficiency of Imported and Domestically Produced Coccidiostatics with Identical Active Substances Biryukov I.M.

Federal Scientific Center "All-Russian Research and Technological Institute of Poultry" of Russian Academy of Sciences

Summary: The anti-coccidial efficiency of imported and domestically produced coccidiostatics with identical active substances (salinomycin, diclazuril, monensin, maduramicin) was comparatively studied with the field coccidial culture containing Eimeria acervulina and E. tenella, isolated from the litter from chicken of different age groups sampled in a Russian poultry farm. The $L D_{50}$ dose of the culture was determined on broilers at 10 days of age. The anticoccidial activity of the preparations was assessed on broilers inoculated with this dose at 12 days of age (6 birds per treatment); the preparations were applied in the day prior to the inoculation and during the subsequent 10 days. Average live bodyweight and weight gains, incidence and causes of mortality cases in broilers were recorded. The anti-coccidial efficiency of the preparations was presented as M.V. Krylov's index of anti-coccidial activity involving survival rate and growth depression in invaded birds. It was found that domestically produced preparations of all studied coccidiostatics and their imported analogues featured similar anti-coccidial activity, the most effective being the preparations of salinomycin.

Key words: coccidiosis, Eimerias, anticoccidial preparations, salinomycin, diclazuril, monensin, maduramicin. 